\title{
Remote haptic perception of slanted surfaces shows the same scale expansion as visual perception
}

\author{
Dennis M. Shaffer • Eric McManama
}

Published online: 17 December 2014

(C) The Psychonomic Society, Inc. 2014

\begin{abstract}
Previous work has shown that overestimates of geographic slant depend on the modality used (verbal or haptic). Recently, that line of reasoning has come into question for many reasons, not the least of which is that the typical method used for measuring "action" has been the use of a palm board, which is not well calibrated to any type of action toward slanted surfaces. In the present work, we investigated how a remote haptic task that has been well calibrated to action in previous work is related to verbal overestimates of slanted surfaces that are out of reach. The results show that haptic estimates are perceptually equivalent to the verbal overestimates that have been found in numerous previous studies. This work shows that the haptic perceptual system is scaled in the same way as the visual perceptual system for estimating the orientation of slanted surfaces that are out of reach.
\end{abstract}

Keywords Spatial vision · Visual perception

For the last 20 years, people's estimates of the orientation of slanted surfaces have been measured both verbally and manually (Bhalla \& Proffitt, 1999; Bridgeman \& Hoover, 2008; Coleman \& Durgin, 2013; Creem-Regehr, Gooch, Sahm, \& Thompson, 2004; Durgin, Hajnal, Li, Tonge, \& Stigliani, 2010; Durgin \& Li, 2012; Durgin, Li, \& Hajnal, 2010; Feresin \& Agostini, 2007; Hajnal, Abdul-Malak, \& Durgin, 2011; Li \& Durgin, 2011; Proffitt, Bhalla, Gossweiler, \& Midgett, 1995; Proffitt, Creem, \& Zosh, 2001; Shaffer, McManama, Swank, \& Durgin, 2013; Stefanucci, Proffitt, Clore, \& Parekh, 2008; Stigliani, Li, \& Durgin, 2013; Taylor-Covill \& Eves).

D. M. Shaffer $(\bowtie) \cdot$ E. McManama

Department of Psychology, Ohio State University,

1760 University Drive, Mansfield, Ohio 44906, USA

e-mail: shaffer.247@osu.edu
All of these studies have documented that people verbally overestimate the slant of hills by between $5^{\circ}$ and $25^{\circ}$, depending on the angle of the slanted surface (Bhalla \& Proffitt, 1999; Creem-Regehr et al., 2004; Proffitt et al., 1995, Proffitt et al., 2001).

In many of these studies, manual estimates have been made using a palm board, which people use by resting a hand on the palm board to match their haptic perception of the palm board to their visual perception of the slope of the hill (e.g., Bhalla \& Proffitt, 1999; Creem-Regehr et al., 2004; Durgin et al., 2010a, b; Feresin \& Agostini, 2007; Proffitt et al., 1995; Proffitt et al., 2001; Stefanucci et al., 2008; Taylor-Covill \& Eves, 2013). More recently, an alternative, free-hand, technique has been used in which estimates are made by holding up an unseen forearm and/or hand to match the slope of the hill proprioceptively (e.g., Bridgeman \& Hoover, 2008; Durgin et al., 2010a, b; Shaffer et al., 2013; Stigliani et al., 2013). Whereas verbal estimates suggest that hills appear much steeper than their physical inclination, palm board estimates are typically fairly accurate in matching the true inclinations of hills, whereas free-hand estimates tend to lie between the palm board and verbal estimates. The reason for the apparent difference between palm board estimates and verbal estimates has been proposed to be the perception-action distinction between visual awareness and visually guided action (Bhalla \& Proffitt, 1999; Creem \& Proffitt, 1998; Proffitt et al., 1995). However, although previous work has claimed that the use of palm boards is a task that measures haptic perception (e.g., Bhalla \& Proffitt, 1999; Proffitt et al., 1995), both palm board and free-hand measures are perceptualmatching tasks to a distal stimulus more than they are true haptic-perception tasks, which allow the hand to explore the slanted surface itself using proprioception and proprioceptive feedback.

One task that has been used for active haptic exploration and the perception of slanted surfaces seems to be ideally 
suited for investigating people's haptic perceptions of slant. This device and experimental setup is a remote haptic device in which the participant holds one end of a wooden dowel ( 1-1.5 $\mathrm{m}$ in length) while exploring an $\sim 1$-m inclined surface (Fitzpatrick, Carello, Schmidt, \& Corey, 1994; Malek \& Wagman, 2008; Regia-Corte \& Wagman, 2008). These studies have investigated the perception of whether a surface affords climbability and standing upright on it (similar to the methodology of Hajnal, Abdul-Malak, \& Durgin, 2011, and Kinsella-Shaw, Shaw, \& Turvey, 1992) by using both verbal and remote haptic measures. This work has produced at least two important findings for the present work. First, the visual and haptic perceptual measures revealed equivalent responses in the perception of slant. Second, the remote haptic measure was very good at assessing whether a person would be able to stand on or climb a slanted surface. This is strong evidence for the remote haptic perception task being an action-based measure, whereas the palm board and free-hand matching tasks lack evidence for being action-related measures for the exploration of slanted surfaces (Durgin et al., 2010a, b).

The first goal of the present experiment was to investigate remote haptic perception of a slanted surface oriented at six different angles and to compare these results to widely recorded verbal overestimates (e.g., Bhalla \& Proffitt, 1999; Durgin \& Li, 2011; Hecht, Shaffer, Keshavarz, \& Flint, 2014; Proffitt et al., 1995; Shaffer \& Flint, 2011; Shaffer et al., 2013). The second goal was to test whether the haptic estimates matched a recent model that has been proposed to explain verbal overestimates and has also been shown to fit people's verbal overestimates of both small artificial surfaces in a laboratory and outdoor hills (Durgin \& Li, 2011, 2012).

\section{Method}

Participants

A total of 50 participants ( 29 male, 21 female) took part in this study, with a mean age of 20.4 years $(S D=4.13)$. Of these, 45 were right-handed. Participants received course credit for their participation.

Materials and apparatus

We created a wooden ramp by connecting two pieces of wood $(1 \mathrm{~m} \times 1 \mathrm{~m})$ with a hinge. We cut six sets of two rods to hold the top portion of the ramp up into one of the six different angles of inclination $\left(5^{\circ}, 18^{\circ}, 30^{\circ}, 42^{\circ}, 45^{\circ}\right.$, and $\left.54^{\circ}\right)$ used in the experiment. After putting the rods in place, we measured the ramp with a digital angle inclinometer to make sure that the desired angles were achieved.

Participants wore occlusion goggles to prevent them from seeing the surface of the ramp or any part of the surrounding
Table 1 Correlations between handedness, height, and arm length and the estimates given

\begin{tabular}{lrrrrrr}
\hline & $5^{\circ}$ & $18^{\circ}$ & $30^{\circ}$ & \multicolumn{1}{c}{$42^{\circ}$} & $45^{\circ}$ & $54^{\circ}$ \\
\hline Handedness & .06 & .07 & -.14 & .05 & .04 & .14 \\
Height & -.12 & .21 & .07 & -.18 & .16 & -.03 \\
Arm length & -.08 & -.24 & .16 & -.12 & .26 & .06 \\
\hline
\end{tabular}

environment. Participants used a wooden dowel $(\sim 1.5 \mathrm{~m}$ in length) to explore the surface of the ramp. The dowel and surface were both visible prior to the start of the experiment, consistent with the procedure of Regia-Corte and Wagman (2008). The surface was set at $0^{\circ}$ when participants first walked in, and was only set to the first angle after participants were wearing the occlusion goggles.

\section{Procedure}

We measured the standing height and arm length of each participant (shoulder to fingertip) prior to the start of the experiment. We also asked each of the participants about their handedness and allowed them to use their dominant hand to hold the dowel. The order of the angles presented to each participant was randomized. We stood participants $0.5 \mathrm{~m}$ away from the ramp, and they were instructed to stand in the same place and explore the surface of the ramp with the dowel until they felt comfortable reporting a numeric estimation of the angle at which the surface was oriented. Participants all made their estimates relative to horizontal. Consistent with the findings of Regia-Corte and Wagman (2008), participants used a variety of exploratory procedures. These included tapping and scraping both side to side and up and down. Although we allowed participants to take as much time as they needed to explore the surface, and although we did not record the amount of time they spent doing this, we can report that generally participants took between $\sim 5$ and 10 s to explore the surface prior to giving their numeric estimate. We had only one restriction of the probing procedures of the participants: They were not allowed to explore outside the surface of the ramp (i.e., to place their dowel between the horizontal portion of the ramp and the oriented surface of the ramp). After giving one numeric estimate, participants were instructed to take the dowel away and place the probing end on the ground next to them prior to being told to explore the surface again.

Table 2 Mean ramp inclination estimates and standard deviations

\begin{tabular}{lllllll}
\hline & $5^{\circ}$ & $18^{\circ}$ & $30^{\circ}$ & $42^{\circ}$ & $45^{\circ}$ & $54^{\circ}$ \\
\hline Mean & $8.52^{\circ}$ & $21.5^{\circ}$ & $38.84^{\circ}$ & $58.04^{\circ}$ & $62.54^{\circ}$ & $77.26^{\circ}$ \\
Standard deviation & $8.94^{\circ}$ & $12.01^{\circ}$ & $14.13^{\circ}$ & $14.8^{\circ}$ & $15.7^{\circ}$ & $8.76^{\circ}$ \\
\hline
\end{tabular}




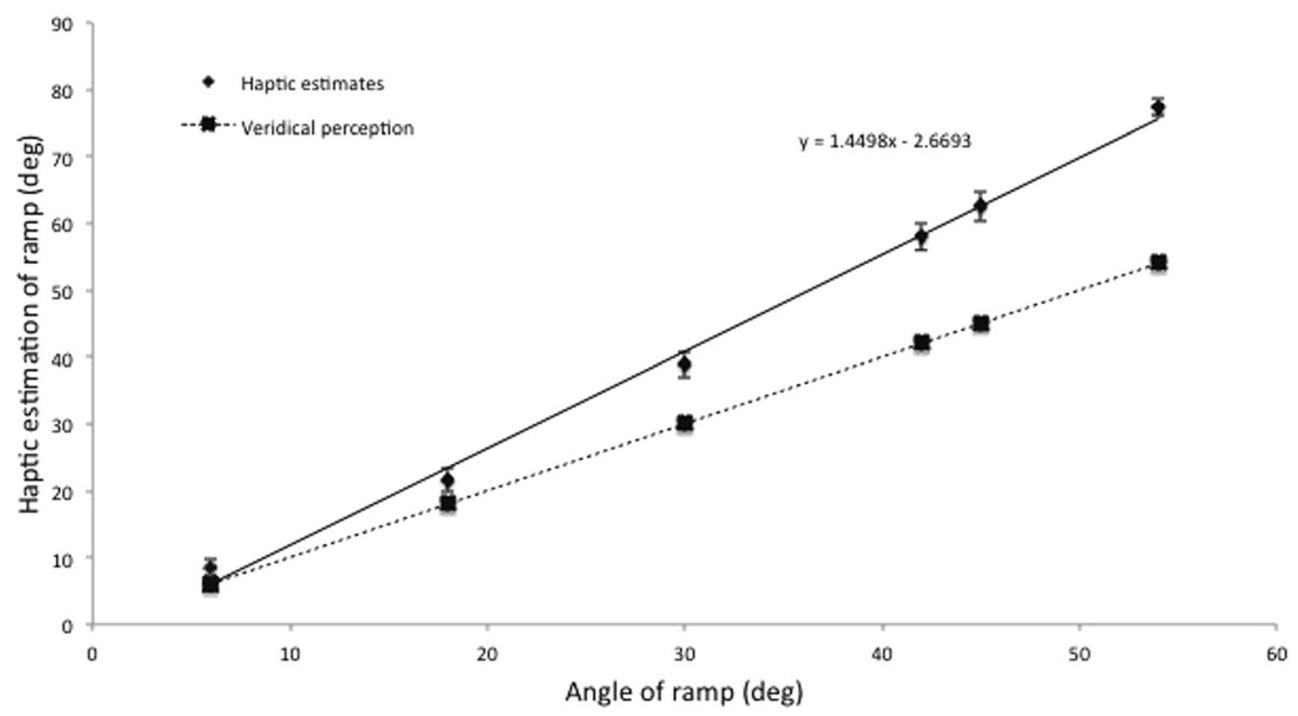

Fig. 1 Mean haptic slant estimates at each angle, with error bars representing $\pm 1 S E M$. The trend line (solid line) shown is the best-fitting linear function. The dotted line indicates how the line would look if people estimated the angles perfectly

\section{Results}

We first wanted to evaluate the effects of the handedness, height, and arm length of participants on their haptic estimates. Therefore, we ran multiple correlations between handedness and the six angles that we used, height and the six angles that we used, and arm length and the six angles that we used. We found no significant correlations between handedness and the estimates given. The correlations are given in Table 1.

In order to test how haptic estimates compared to the actual angles of the ramp given for all orientations, we performed six one-sample $t$ tests comparing participants' estimates to the actual angles of the ramp. The six one-sample $t$ tests revealed that the haptic estimates were significantly greater than the actual angles of the ramp for all six angles: $5^{\circ}, t(49)=2.78, p$ $=.0076 ; 18^{\circ}, t(49)=2.061, p=.0446 ; 30^{\circ}, t(49)=4.42, p<$ $.0001 ; 42^{\circ}, t(49)=7.66, p<.0001 ; 45^{\circ}, t(49)=7.9, p<.0001$; and $54^{\circ}, t(49)=18.77, p<.0001 .^{1}$ Even with a conservative Bonferroni-corrected $p$ value (.0083), all but one of the comparisons was reliable. The ramp inclination mean estimates are given in Table 2.

To test whether the proportional biases at different slopes differed reliably by slope, we ratio-scaled the slants (i.e., calculated a ratio of the slant estimates relative to the actual inclination of the ramp) for each participant, and then performed a

\footnotetext{
${ }^{1}$ In a separate data collection, we recorded 40 participants' verbal estimates of the same inclinations of the ramp used in the present study. After plotting the means of the verbal estimates, we fitted a regression line to the data that accounted for over $99 \%$ of the variance and had a gain of 1.4897 , similar to the gain of 1.4498 found in the present work with the hand-held rod, and similar to the 1.5 gains that are consistently found with outdoor hills.
}

repeated measures analysis of variance (ANOVA) on the ratioscaled slants. Mauchly's test indicated that sphericity had been violated, $\chi^{2}(14)=258.93, p<.001$; therefore, the degrees of freedom were corrected using Greenhouse-Geisser estimates of sphericity $(\varepsilon=0.3)$. No significant differences were found among the ratio-scaled slants, $F(1.48,72.42)=2.32, p=.12$.

\section{Discussion}

We have shown that a remote haptic perception response measure overestimates a slanted surface at all orientations from $5^{\circ}$ to $54^{\circ}$, much as verbal estimates have been shown to overestimate slanted surfaces across numerous studies (Bhalla \& Proffitt, 1999; Bridgeman \& Hoover, 2008; Durgin \& Li, 2011; Proffitt et al., 1995; Shaffer et al., 2013; Shaffer, McManama, Swank, Williams, \& Durgin, 2014). Unlike previous work in which matching tasks have been used to approximate the orientation of slanted surfaces, in the present methodology we used a remote haptic task that allowed for exploration of the entire surface and did not have the restrictions of some of the previous methods (e.g., Bhalla \& Proffitt, 1999; Proffitt et al., 1995). This method has been shown to afford appropriate action upon the same slanted surfaces on which it is used (Malek \& Wagman, 2008; Regia-Corte \& Wagman, 2008). Additionally, this work has shown that similar results are obtained whether perception of an inclined surface is measured by viewing it or probing it with a handheld rod. These results suggest that the perception of inclined surfaces is modality-independent, consistent with the findings in the present work. The one difference between the present work and the previous work is that in the previous work people estimated the steepest angle of the surface that would 
allow them to stand on it with an upright posture. In the present work, we asked people to estimate the exact angle at which the surface was inclined. Thus, it is possible that a combination of conscious and action-based processes is used to translate an action-based measure to a verbal estimate. The main reason that we feel that this is not the case is that exploring an inclined surface with a hand-held rod is not a common type of action that is likely to have been calibrated directly to conscious visual processes. Therefore, we believe that the exaggeration of slant shown in our work affects the representation of space generally.

One of the goals of the present work was to test how well these data fit a recently proposed model that has been shown to fit outdoor hills and indoor surfaces alike (Durgin, 2014; Durgin \& Li, 2011, 2012). Durgin and Li (2012) showed that perceived slant exaggerates actual slant by a factor of about 1.5 for a range of angles up to $60^{\circ}$. In order to test whether the model proposing the 1.5 gain that has been shown for verbal estimates, nonverbal matching estimates, and haptic estimates using a finger (see Durgin \& Li, 2012; Hajnal et al., 2011) fit our data, we plotted the six angles used in the present experiment against the mean remote haptic estimates of those six angles. The estimates are presented in Fig. 1, and they fit a straight line very well, $R^{2}=.995$.

As is shown on the figure, the slope, or gain, for the estimates is almost exactly equal to 1.5 , as predicted by the Durgin and Li (2012) model for slant estimation.

The present work provides a more general case of exaggerated haptic slant perception of a surface that is out of reach. The data show that the perceptual experience is pretty similar to the haptic and visual experiences that have been studied in the prior research cited by the authors. We point out that this is not a common type of action that is likely to have been calibrated to visual experience directly, and thus that the underlying bias (slant exaggeration) appears to be one affecting the representation of space generally.

The present work shows that the remote haptic perception task is a well-calibrated action measure and is scaled very closely to verbal estimates for the perception of slanted surfaces. This lends support for the idea that our visual system is scaled in the same way as our haptic system, resulting in a common underlying perceptual experience.

Author note We thank Charles Swank, Ally Taylor, and Phil Graves for their assistance in the experimental setup and data collection.

\section{References}

Bhalla, M., \& Proffitt, D. R. (1999). Visual-motor recalibration in geographical slant perception. Journal of Experimental Psychology: Human Perception and Performance, 25, 1076-1096. doi:10. 1037/0096-1523.25.4.1076
Bridgeman, B., \& Hoover, M. (2008). Processing spatial layout by perception and sensorimotor interaction. Quarterly Journal of Experimental Psychology, 61, 851-859.

Coleman, A., \& Durgin, F. H. (2013). Egocentric reference frame bias in the palmar haptic perception of surface orientation. Psychonomic Bulletin \& Review, 21, 955-960. doi:10.3758/s13423-013-0552-7

Creem, S. H., \& Proffitt, D. R. (1998). Two memories for geographical slant: separation and interdependence of action and awareness. Psychonomic Bulletin \& Review, 5, 22-36. doi:10.3758/ BF03209455

Creem-Regehr, S. H., Gooch, A. A., Sahm, C. S., \& Thompson, W. B. (2004). Perceiving virtual geographical slant: Action influences perception. Journal of Experimental Psychology: Human Perception and Performance, 30, 811-821.

Durgin, F. H. (2014). Angular scale expansion theory and the misperception of egocentric distance in locomotor space. Psychology and Neuroscience, 7, 253-260.

Durgin, F. H., \& Li, Z. (2011). Perceptual scale expansion: An efficient angular coding strategy for locomotor space. Attention, Perception, \& Psychophysics, 73, 1856-1870.

Durgin, F. H., \& Li, Z. (2012). Spatial biases and the haptic experience of surface orientation. In A. El Saddik (Ed.), Haptics rendering and applications (pp. 75-94). Rijeka, Croatia: Intech.

Durgin, F. H., Hajnal, A., Li, Z., Tonge, N., \& Stigliani, A. (2010a). Palm boards are not action measures: An alternative to the two-systems theory of geographical slant perception. Acta Psychologica, 134, 182-197.

Durgin, F. H., Li, Z., \& Hajnal, A. (2010b). Slant perception in near space is categorically biased: Evidence for a vertical tendency. Attention, Perception, \& Psychophysics, 72, 1875-1889. doi:10.3758/APP.72. 7.1875

Feresin, C., \& Agostini, T. (2007). Perception of visual inclination in a real and simulated urban environment. Perception, 36, 258-267.

Fitzpatrick, P., Carello, C., Schmidt, R. C., \& Corey, D. (1994). Haptic and visual perception of an affordance from upright posture. Ecological Psychology, 6, 265-287.

Hajnal, A., Abdul-Malak, D. T., \& Durgin, F. H. (2011). The perceptual experience of slope by foot and by finger. Journal of Experimental Psychology: Human Perception and Performance, 37, 709-719. doi:10.1037/a0019950

Hecht, H., Shaffer, D. M., Keshavarz, B., \& Flint, M. (2014). Slope estimation and viewing distance of the observer. Attention, Perception, \& Psychophysics, 76, 1729-1738. doi:10.3758/ s13414-014-0702-7

Kinsella-Shaw, J. M., Shaw, B., \& Turvey, M. T. (1992). Perceiving "walk-on-able" slopes. Ecological Psychology, 4, 223-239.

Li, Z., \& Durgin, F. H. (2011). Design, data and theory regarding a digital hand inclinometer: A portable device for studying slant perception. Behavior Research Methods, 43, 363-371. doi:10.3758/s13428010-0047-7

Malek, E. A., \& Wagman, J. B. (2008). Kinetic potential influences visual and remote haptic perception of affordances for standing on an inclined surface. Quarterly Journal of Experimental Psychology, 61, 1813-1826.

Proffitt, D. R., Bhalla, M., Gossweiler, R., \& Midgett, J. (1995). Perceiving geographical slant. Psychonomic Bulletin \& Review, 2, 409-428.

Proffitt, D. R., Creem, S. H., \& Zosh, W. D. (2001). Seeing mountains in mole hills: Geographical-slant perception. Psychological Science, 12, 418-423.

Regia-Corte, T., \& Wagman, J. B. (2008). Perception of affordances for standing on an inclined surface depends on height of center of mass. Experimental Brain Research, 191, 25-35.

Shaffer, D. M., \& Flint, M. (2011). Escalating slant: Increasing physiological potential does not reduce slant overestimates. 
Psychological Science, 22, 209-211. doi:10.1177/ 0956797610393744

Shaffer, D. M., McManama, E., Swank, C., \& Durgin, F. H. (2013). Sugar and space? Not the case: Effects of low blood glucose on slant estimation are mediated by beliefs. i-Perception, 4, 147-155.

Shaffer, D. M., McManama, E., Swank, C., Williams, M., \& Durgin, F. H. (2014). Anchoring in action: Manual estimates of slant are powerfully biased toward initial hand orientation and are correlated with verbal report. Journal of Experimental Psychology: Human Perception and Performance, 40, 1203-1212. doi:10.1037/a0036217
Stefanucci, J. K., Proffitt, D. R., Clore, G. L., \& Parekh, N. (2008). Skating down a steeper slope: Fear influences the perception of geographical slant. Perception, 37, 321-323.

Stigliani, A., Li, Z., \& Durgin, F. H. (2013). Humans have precise knowledge of familiar geographical slants. Journal of Experimental Psychology: Learning, Memory, and Cognition, 39, 1966-1973.

Taylor-Covill, G. A. H., \& Eves, F. F. (2013). The accuracy of "haptically" measured geographical slant perception. Acta Psychologica, 144, 444-450. 